\title{
Validação de conjuntos diagnósticos comerciais para dosagem sérica de progesterona e estradiol em jaguatirica (Leopardus pardalis) e gato-do-mato- pequeno (Leopardus tigrinus)
}

Regina Celia Rodrigues da PAZ ${ }^{1}$

Cristina Harumi ADANIA ${ }^{2}$

Cláudio Alvarenga de

OLIVEIRA $^{3}$

Renato Campanarut

BARNABE $^{3}$

\section{Correspondência para:}

Regina Celia Rodrigues da Paz, Faculdade de Agronomia e Medicina Veterinária UniversidadeFederal de Mato Grosso, Rua Fernando Correa da Costa s $/ \mathrm{n}^{\circ}$ - Coxipó Cuiabá / MT, 78060-600, Fone: (65) 36158681 Fax: (65) 36158614 Celular (65) 92141266, reginacrpaz@gmail.com

Recebido para publicação: 29/11/2007 Aprovado para publicação: 29/06/2009

\author{
1 - Departamento de Ciências Básicas e Produção Animal da Faculdade de \\ Agronomia e Medicina Veterinária da Universidade Federal do Mato Grosso, \\ Cuiabá-MT \\ 2 - Associação Mata Ciliar, Jundiaí-SP \\ 3 - Departamento de Reprodução Animal da Faculdade de Medicina Veterinária e \\ Zootecnia da Universidade de São Paulo, São Paulo-SP
}

\section{Resumo}

Este estudo teve como objetivo validar os conjuntos diagnósticos comerciais DPC (Coat-A-Count - Diagnostic Products Corporation/ USA), em fase sólida, para dosagem de progesterona e DSL (Diagnostic System Laboratories INC/USA), em fase líquida, para dosagem de estradiol, por radioimunoensaio, em soro de Leopardus pardalis $(\mathrm{n}=5)$ e Leopardus tigrinus ( $\mathrm{n}=4)$, antes (15-30 dias) e após (24-28 horas) tratamento com gonadotropinas exógenas (hCG/ Novormon ${ }^{\circledR} \mathrm{e}$ eCG/ Vetecor ${ }^{\circledR}$; pFSH/Folltropin-V ${ }^{\circledR}$ e pLH/Lutropin-V ${ }^{\circledR}$ ). A concentração sérica para Leopardus pardalis variou 0,005 a $0,151 \mathrm{ng} / \mathrm{ml}$ para estradiol e $0,15-37,22 \mathrm{ng} / \mathrm{ml}$ para progesterona. A concentração sérica para Leopardus tigrinus variou 0,012-0,147ng/ml para estradiol e 0,06-34,09ng/ml para progesterona. A sensibilidade mínima detectada foi $0,004 \mathrm{ng} / \mathrm{ml}$ para progesterona e $0,00014 \mathrm{ng} / \mathrm{ml}$ para estradiol. Para progesterona o coeficiente intra-ensaio baixo foi $2,58 \%$ e alto $6,36 \%$, já o coeficiente inter-ensaio baixo foi $0,67 \%$ e alto 5,55\%. Para o estradiol o coeficiente intra-ensaio baixo foi $0,69 \%$ e alto $4,15 \%$, sendo o coeficiente inter-ensaio baixo $1,40 \%$ e alto 3,00\%. Paralelismo foi encontrado para progesterona e conjunto comercial DPC com $\mathrm{r}=0,96$ para Leopardus pardalis e $\mathrm{r}=0,99$ para Leopardus tigrinus. Para estradiol em conjunto comercial DSL paralelismo foi encontrado com $\mathrm{r}=0,98$ para Leopardus pardalis e com $\mathrm{r}=0,99$ para Leopardus tigrinus. Com estes resultados podemos concluir que o conjunto diagnóstico comercial DPC para dosagem de progesterona e DSL para dosagem de estradiol foram validados para utilização em soro de Leopardus pardalis e Leopardus tigrinus, podendo ser utilizado como ferramenta no manejo reprodutivo destas espécies visando à conservação.

\section{Introdução}

A sazonalidade reprodutiva é variável entre as diferentes espécies de felídeos. As que ocorrem em regiões cuja latitude é alta, como os tigres (Panthera tigris) apresentam uma estação bem definida para nascimento de seus filhotes, entre verão e outono. ${ }^{1}$ Espécies tropicais podem apresentar maiores concentrações de nascimentos durante determinadas épocas do ano, mas normalmente são capazes de reproduzir durante o ano todo. ${ }^{2}$ Em gatos domésticos (Felis catus), o fenômeno da estacionalidade está intimamente ligado ao fotoperíodo ${ }^{1,3,4}$, porém em felídeos selvagens, este fator também está relacionado à maior ou menor oferta de alimento durante as estações do ano². 
Outro aspecto que parece variar entre as diferentes espécies de felídeos é o mecanismo de ovulação. Estudos que utilizaram dosagens hormonais séricas ou plasmáticas confirmaram que algumas espécies selvagens como tigre (Panthera tigris) ${ }^{1}$, leopardo das neves (Panthera uncia) ${ }^{5}$, onçapintada (Panthera onca) ${ }^{6}$ e puma (Puma (oncolor $)^{7}$, possuem mecanismos de ovulação reflexa ou induzida, assim como a gata doméstica ${ }^{3,4}$. No entanto, fêmeas de leopardo (Panthera pardus) apresentaram os dois mecanismos de ovulação em duas diferentes situações. Quando mantidas isoladas, mostraram perfil hormonal típico de ovuladoras reflexas, porém, quando alojadas em duplas de fêmeas, ovularam provavelmente estimuladas pelo contato físico entre elas ${ }^{8}$, o que acontece também com gatas domésticas. Fêmeas do gênero Leopardus são poliéstricos e podem ciclar durante o ano todo ${ }^{9,10}$, sendo o gato maracajá (Leopardus wiedii) o único no gênero a apresentar maior freqüência de ovulações espontâneas ${ }^{10}$.

Dessa forma, técnicas imunológicas vêm sendo cada vez mais utilizadas na dosagem de hormônios reprodutivos em animais silvestres, para caracterizar sua fisiologia reprodutiva. $\mathrm{O}$ radioimunoensaio (RIE) é uma técnica altamente sensível e baseia-se na competição entre um antígeno marcado (elemento traçador) e não marcado (hormônio). A validação do ensaio é o primeiro passo para se estabelecer um estudo endócrino apropriado. Sua qualidade e consistência são necessárias para assegurar a relevância biológica dos resultados.

Nesse sentido, a validação de conjuntos diagnósticos comerciais para dosagem de hormônios reprodutivos fornecerá subsídios necessários ao estudo da fisiologia reprodutiva de espécies ameaçadas de extinção, facilitando o estabelecimento de uma estratégia de manejo reprodutivo visando sua conservação.

O objetivo deste trabalho foi validar os conjuntos diagnósticos comerciais DPC (Coat-A-Count - Diagnostic Products Corporation/USA), em fase sólida, para dosagem de progesterona e DSL (Diagnostic System Laboratories INC/ USA), em fase líquida, para dosagem de estradiol, em soro de Leopardus pardalis e Leopardus tigrinus, antes e após estimulação hormonal com gonadotropinas exógenas (hCG-Gonadotropina Coriônica humana/ Novormon ${ }^{\circledR}$ e eCG-Gonadotropina Coriônica eqüina/ Vetecor ${ }^{\circledR}$; pFSHHormônio Folículo Estimulante suíno/ Folltropin- $\mathrm{V}^{\circledR}$ e pLH-Hormônio Luteinizante suíno/Lutropin- $\mathrm{V}^{\circledR}$ ).

\section{Material e Método}

Foram utilizadas cinco fêmeas de Leopardus pardalis (Studbook número: 240, 254, 285, 289, 290); e quatro fêmeas de Leopardus tigrinus (Studbook número: 134, 136, 138 e 141), alojadas na Associação Mata Ciliar, localizada em Jundiaí/SP.

As fêmeas de gato-do-mato-pequeno foram mantidas no mesmo recinto e as fêmeas de jaguatirica aos casais, sendo que durante o período de tratamento hormonal as fêmeas eram mantidas no cambiamento. Os animais eram alimentados diariamente com pescoço de frango, duas vezes por semana com ratos de descarte e esporadicamente com suplemento vitamínico (Aminomix/Vetnil ${ }^{\circledR}$ ).

A partir da $4^{a}$ estimulação ovariana a fêmea 138 veio a óbito em decorrência de brigas freqüentes com a fëmea 134. Durante o período experimental duas fêmeas de jaguatirica (254 e 285) ficaram prenhes, impossibilitando a realização do protocolo de estimulação ovariana durante o período de gestação.

Este experimento foi submetido e aprovado pelo Comitê do Plano de Manejo para Pequenos Felinos Brasileiros em 22 de setembro de 2000, portaria IBAMA n ${ }^{\circ} 106 /$ 1995 e Termo de Cooperação Técnica IBAMA/CENAP/AMC n ${ }^{\circ} 2 / 2000$ e obteve licença CITES/IBAMA nº108862. Foi também submetido à Comissão de Bioética da Faculdade de Medicina Veterinária e Zootecnia da Universidade de São Paulo Protocolo no 109/2002, sendo aprovado na sessão do dia 05 de junho de 2002. 
Todos os animais passaram por todos os tratamentos, sendo que cada animal foi estimulado por três vezes com o mesmo protocolo alternadamente.

Jaguatirica - Tratamento 1: 225 UI hCG (IM), 80 h após a administração de 500 UI eCG (IM), sendo a colheita de sangue realizada 15-30 dias antes e 24-28 h após a administração do hCG. Tratamento 2: 50 UI pFSH (IM), administrados gradativamente, em quatro dias consecutivos, com intervalos de 14 h (20UI), 24 h (15UI), 24 h (10UI) e $18 \mathrm{~h}$ (5UI), respectivamente. No dia cinco, 18 horas após a administração da última dose de pFSH, foi aplicada uma dose de 20 UI de pLH (IM), sendo a colheita de sangue realizada 15-30 dias antes e 24-28 h após a administração do $\mathrm{pLH}^{11,12}$.

Gato-do-mato-pequeno - Tratamento 1: 75 UI hCG (IM), 80 h após a administração de 100 UI eCG (IM), sendo a colheita de sangue realizada 15-30 dias antes e 24-28 h após a administração do hCG. Tratamento 2: 30 UI pFSH (IM), administrados gradativamente, em quatro dias consecutivos, com intervalos de $14 \mathrm{~h}$ (12UI), $24 \mathrm{~h}$ (9UI), $24 \mathrm{~h}(6 \mathrm{UI})$ e $18 \mathrm{~h}$ (3UI), respectivamente. No dia cinco, 18 h após a administração da última dose de $\mathrm{pFSH}$, foi aplicada uma dose de 10 UI de pLH (IM), sendo a colheita de sangue realizada 15-30 dias antes e 24-28 h após a administração do pLH ${ }^{11,12}$.

O sangue foi obtido por punção venosa imediatamente após a imobilização química dos animais. Em seguida, foi centrifugado para separação do soro, o qual foi recolhido, identificado e armazenado em freezer $\left(-20^{\circ} \mathrm{C}\right)$ até o momento das análises. Foram realizadas análises hormonais para determinação dos níveis séricos de progesterona e estradiol em duplicata pela técnica de radioimunoensaio (RIE) no Laboratório de Dosagens Hormonais do Departamento de Reprodução Animal da Faculdade de Medicina Veterinária e Zootecnia da Universidade de São Paulo (LDH/VRA/FMVZ/USP).

Para progesterona foi utilizado conjunto diagnóstico comercial Coat-ACount DPC - Diagnostic Products
Corporation/USA, em fase sólida e para estradiol foi utilizado conjunto diagnóstico comercial DSL - Diagnostic System Laboratories INC/USA, em fase líquida. Os procedimentos utilizados para as dosagens hormonais foram os mesmos especificados pelo fabricante, sendo que este conjunto diagnóstico utiliza como elemento traçador o hormônio marcado com ${ }^{125} \mathrm{I}$. A radioatividade foi medida por contador automático (Autogama Cobra Packard) para determinação da curva padrão e dosagens do ensaio.

O controle de qualidade dos ensaios de RIE foi realizado através da análise dos coeficientes de variação intra e inter-ensaio, sendo que no $\mathrm{LDH}$ índices aceitáveis não devem ultrapassar $10 \%$.

A validação dos conjuntos diagnósticos comerciais para uso em soro de fêmeas de jaguatirica e gato-do-matopequeno foi realizada de acordo com o método de paralelismo utilizando matriz depletada. Para tanto, foi realizada a depleção hormonal de um pool de amostras com uma solução de carvão-dextran ${ }^{13,14}$. A essa matriz depletada adicionamos valores conhecidos do hormônio padrão, com diluições que se aproximavam dos pontos da curva do conjunto diagnóstico. Com essa diluição construímos uma curva correlacionando estes valores.

\section{Resultados}

A concentração sérica de estradiol encontrada para jaguatiricas neste experimento variou de 0,005 a $0,151 \mathrm{ng} / \mathrm{ml}$ e a concentração sérica de progesterona variou de 0,15 a 37,22 $\mathrm{ng} / \mathrm{ml}$. A concentração sérica de estradiol encontrada para gato-do-mato-pequeno neste experimento variou de 0,012 a $0,147 \mathrm{ng} / \mathrm{ml}$ e a concentração sérica de progesterona variou de 0,06 a 34,09 $\mathrm{ng} / \mathrm{ml}$.

A sensibilidade mínima detectada foi de $0,004 \mathrm{ng} / \mathrm{ml}$ para progesterona e de 0,00014 ng/ml para estradiol. Para o controle de qualidade foram utilizados pontos de concentração baixa e pontos de concentração alta dos hormônios mensurados. Para 
progesterona o coeficiente intra-ensaio baixo foi de $2,58 \%$ e alto foi de $6,36 \%$, já o coeficiente inter-ensaio baixo foi de $0,67 \%$ e alto foi de 5,55\%. Para o estradiol o coeficiente intra-ensaio baixo foi de $0,69 \%$ e alto foi de $4,15 \%$, sendo o coeficiente interensaio baixo de $1,40 \%$ e alto de 3,00\%.

A validação dos conjuntos diagnósticos comerciais utilizados foi realizada utilizando-se a curva de paralelismo, sendo que para haver paralelismo o coeficiente de correlação (r) deve ficar próximo a 1 e nunca ser inferior a 0,95 segundo o padrão seguido pelo $\mathrm{LDH} /$ VRA/FMVZ/USP.

Paralelismo foi encontrado entre as curvas de diluição de progesterona na matriz depletada e a curva do conjunto comercial DPC (Coat-A-Count - Diagnostic Products Corporation/USA), com $r=0,96$ e entre

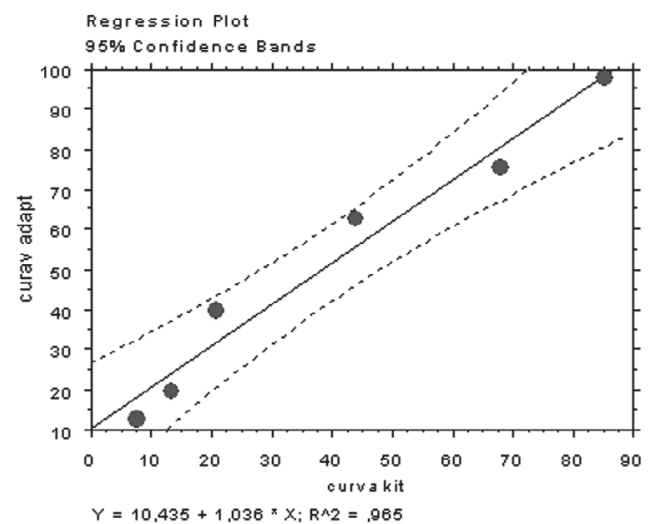

as curvas de diluição de estradiol na matriz depletada e a curva do conjunto comercial DSL (Diagnostic System Laboratories INC/ USA), com $r=0,98$ para jaguatiricas (Figura 1).

Paralelismo foi encontrado entre as curvas de diluição de progesterona na matriz depletada e a curva do conjunto comercial DPC (Coat-A-Count - Diagnostic Products Corporation/USA), com $r=0,99$ e entre as curvas de diluição de estradiol na matriz depletada e a curva do conjunto comercial DSL (Diagnostic System Laboratories INC/ USA), com $r=0,99$ para gato-do-matopequeno (Figura 2).

\section{Discussão}

A validação do radioimunoensaio é utilizada para verificar a quantidade de

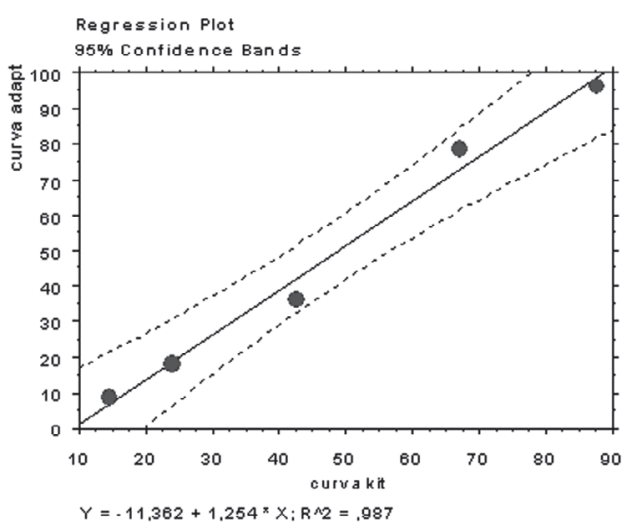

Figura 1 - Representação gráfica da curva de paralelismo obtida para jaguatiricas, progesterona à esquerda e estradiol à direita, utilizando matriz depletada - São Paulo - 2004
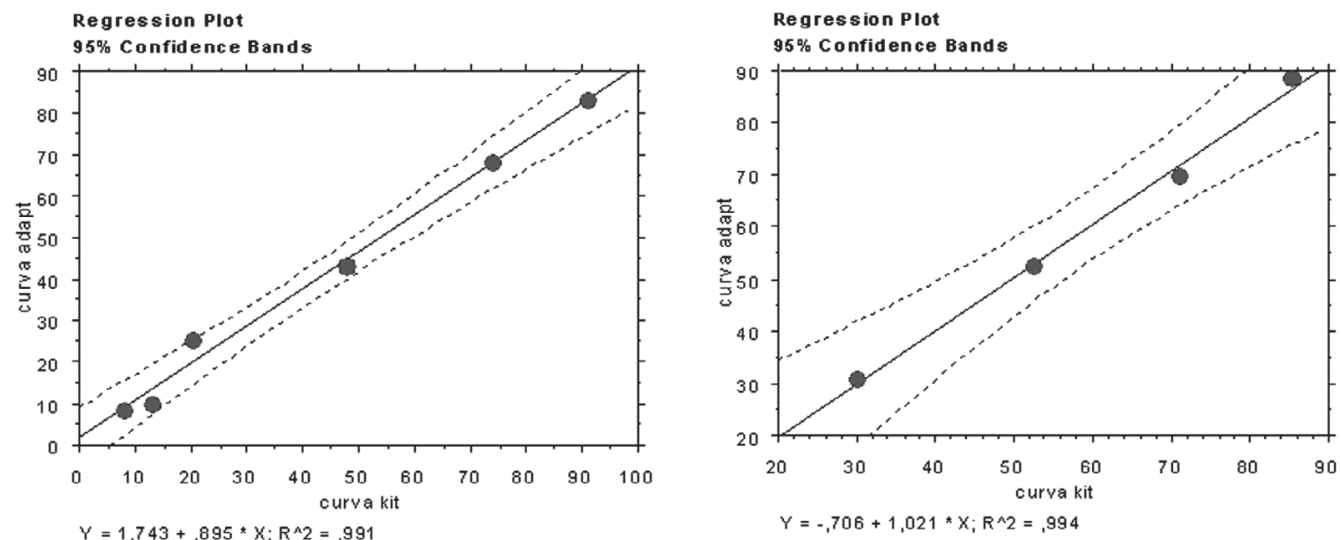

Figura 2 - Representação gráfica da curva de paralelismo obtida para fêmeas gato-do-mato-pequeno, progesterona à esquerda e estradiol à direita, utilizando matriz depletada - São Paulo - 2004 
hormônio detectado e possíveis interferências no ensaio. $\mathrm{O}$ primeiro passo para a validação é a verificação do paralelismo com a curva padrão. A curva padrão indica a sensibilidade do ensaio, ou seja, verifica-se a correlação entre quantidade de hormônio detectada e a diluição correta da amostra. Testes de recuperação são utilizados para verificar uma possível interferência e indicam o quanto à concentração mensurada corresponde a verdadeira concentração.

Segundo o padrão seguido pelo LDH/VRA/FMVZ/USP para haver paralelismo o coeficiente de correlação (r) deve ficar próximo a 1 e nunca ser inferior a 0,95 . Outros laboratórios indicam valores aceitáveis de recuperação entre 0,85 a 1,15 ${ }^{15}$, e 0,9 a $1,10^{16}$.

Em nosso ensaio foi verificado paralelismo entre a curva padrão do conjunto diagnóstico e a curva obtida a partir do pool de soro das fêmeas de jaguatirica e gato-do-mato-pequeno para progesterona e estradiol. Os valores (r) encontrados ficaram entre 0,96 e 0,99 validando o uso dos conjuntos diagnósticos comerciais utilizados, DPC (Coat-A-Count - Diagnostic Products Corporation/USA) e DSL (Diagnostic System Laboratories INC/USA).

O controle de qualidade do ensaio é dado pelo coeficiente de variação $(\mathrm{CV})$, que pode ser intra ou inter-ensaio. $\mathrm{O}$ coeficiente de variação intra-ensaio determina o erro associado a dosagem da mesma amostra em um ensaio (duplicata ou triplicata) e o interensaio determina o erro observado quando a mesma amostra é dosada em diferentes ensaios. Os coeficientes de variação intra e inter-ensaio não devem ultrapassar 10\% segundo os critérios utilizados no $\mathrm{LDH} /$ VRA/FMVZ/USP. Outros laboratórios também definem como nível de erro aceitável a porcentagem fixa de no máximo $10 \%$ para $\mathrm{CV} .^{15}$

Causas de alteração no coeficiente de variação intra-ensaio geralmente resultam da presença inadequada de amostra ou elemento traçador, podendo também ser decorrentes de erros na pipetagem e homogeneização insuficiente da amostra ou reagente. Causas de alteração no coeficiente de variação inter-ensaio podem ser decorrentes de problemas relacionados a instabilidade dos reagentes ou erros na curva padrão. ${ }^{15}$

Neste experimento os coeficientes de variação intra e inter-ensaio não ultrapassaram $6 \%$, indicando que o procedimento foi realizado dentro dos critérios de qualidade esperados.

As análises hormonais séricas foram representadas pelo conjunto de amostras colhidas em intervalos de 15 a 30 dias antes e 24 a 28 horas após tratamento hormonal, ou seja, amostras pontuais e com animais sob efeito anestésico. No entanto, podemos observar que as dosagens hormonais séricas demonstraram um aumento nos níveis de estradiol após o tratamento hormonal. Elevações de progesterona foram observadas em alguns momentos pré e pós tratamento, sendo evidente sua elevação na fêmea prenhe.

Os níveis de progesterona elevados, encontrados em fêmeas não gestantes, podem ser decorrentes do estresse gerado pelas contenções necessárias para realização das estimulações ovarianas e colheitas de material, onde um estímulo estressante desencadearia uma produção elevada de progesterona pela adrenal. Por serem animais ferozes e por estarem alojados em recintos com galhos e casinha de madeira suspensa, as fêmeas escalavam pelos galhos em direção à casa suspensa, o que dificultava a contenção física, que por vezes era demorada e indutora de estresse aos animais.

Há relatos que situações estressantes podem levar a um rápido aumento de progesterona sérica. Em estudo realizado em cervo-dama (Dama dama) houve um aumento expressivo na concentração sérica de progesterona após a administração de ACTH. ${ }^{17}$ Também houve um aumento nas concentrações séricas de progesterona após a contenção de leoas (Panthera leo) com implante contraceptivo ${ }^{18}$, evidenciando a participação da glândula adrenal na síntese 
de progesterona após situações estressantes. Neste caso, o aumento dos níveis de progesterona pode estar relacionado ao estresse da captura nas fêmeas não gestantes. No entanto, para podermos afirmar que essa relação ocorre em jaguatirica e gato-domato-pequeno haveria necessidade de estimulação exógena com ACTH.

A fase de crescimento folicular em gatas domésticas é caracterizada por apresentar aumentos gradativos na concentração sérica de estradiol que variou entre 20 a $70 \mathrm{pg} / \mathrm{ml}$, do primeiro ao último dia do estro, sendo que picos de estradiol superiores a $70 \mathrm{pg} / \mathrm{ml}$ foram observados algumas vezes. ${ }^{19}$

O estro em jaguatiricas foi caracterizado por apresentar concentrações séricas de estradiol que variaram entre 59,84 a 305,77 $\mathrm{pg} / \mathrm{ml}$ acompanhadas de concentrações séricas de progesterona que variaram entre 0,11 a $2,61 \mathrm{ng} / \mathrm{ml} .{ }^{20} \mathrm{Em}$ fêmeas de jaguatiricas, avaliadas após superovulação, as concentrações séricas de estradiol variaram entre 115,9 a 513,6 pg/ml e as concentrações séricas de progesterona variaram entre 250 a $510 \mathrm{pg} / \mathrm{ml}^{20}$. Neste experimento a concentração sérica de estradiol encontrada para jaguatiricas foi inferior à encontrada na literatura, variando de 0,5 a $15,1 \mathrm{pg} / \mathrm{ml}$, no entanto, apresentou valores superiores quanto à concentração sérica de progesterona que variou de 15 a $3722 \mathrm{pg} / \mathrm{ml}$.

Em fêmeas de gato-do-matopequeno superovulados as concentrações séricas de estradiol foram de 60,1 e 121,0 $\mathrm{pg} / \mathrm{ml}$ e as concentrações séricas de progesterona foram de 370 e $1360 \mathrm{pg} / \mathrm{ml} .^{21}$
A concentração sérica de estradiol encontrada para fêmeas de gato-do-matopequeno neste experimento também foi inferior à encontrada na literatura, variando de 1,2 a $14,7 \mathrm{pg} / \mathrm{ml}$ e a concentração sérica de progesterona apresentou-se superior variando de 6 a $3409 \mathrm{pg} / \mathrm{ml}$.

Graham, Swanson e Brown ${ }^{22}$ demonstraram que estimulação ovariana utilizando gonadotropinas exógenas em gatas domésticas resultou em padrão anormal de estrógenos fecais, com concentrações mais altas e persistentes quando comparadas com as de animais em estro natural. Folículos acessórios e corpos lúteos secundários tem sido documentados em gatas estimuladas, causando um ambiente endócrino anormal. No entanto, concentrações de progesterona elevadas, encontradas em fêmeas não prenhes, não interferiram na resposta ovariana após tratamentos hormonais consecutivos ${ }^{23}$.

\section{Conclusão}

O conjunto diagnóstico comercial DPC (Coat-A-Count Diagnostic Products Corporation/USA), em fase sólida, para dosagem de progesterona e o conjunto diagnóstico comercial DSL (Diagnostic System Laboratories INC/USA), em fase líquida, para dosagem de estradiol, foram validados para utilização em soro de Leopardus pardalis e Leopardus tigrinus.

\section{Agradecimentos}

À Fundação de Amparo e Pesquisa do Estado de São Paulo pelo apoio financeiro.

\section{Progesterone and estradiol commercial kits validation in serum of ocelots (Leopardus pardalis) and tigrina (Leopardus tigrinus)}

\section{Abstract}

DPC commercial kit (Coat-A-Count - Diagnostic Products Corporation/USA) and DSL commercial kit (Diagnostic System Laboratories INC/USA) were used for progesterone and estradiol radioimmunoassay validation in serum of two endangered Brazilian felids: Leopardus pardalis ( $\mathrm{n}=5$ ) and Leopardus tigrinus ( $\mathrm{n}=4)$ before (15-
Key words: Wildlife animals. Radioimmunoassay. Progesterone. Estradiol. 
30 days) and after (24-28 hours) exogenous gonadotrophins treatment (hCG/ Novormon ${ }^{\circledR}$ and eCG/ Vetecor ${ }^{\circledR}$; pFSH/Folltropin- $V^{\circledR}$ and $\mathrm{pLH} /$ Lutropin- $\mathrm{V}^{\circledR}$ ). Variation of estradiol concentration was 0.005 $0.151 \mathrm{ng} / \mathrm{ml}$ and progesterone concentration was $0.15-37.22 \mathrm{ng} / \mathrm{ml}$ for Leopardus pardalis. Variation of estradiol concentration was 0.012 $0.147 \mathrm{ng} / \mathrm{ml}$ and progesterone concentration was $0.15-37.22 \mathrm{ng} / \mathrm{ml}$ for Leopardus tigrinus. Minimum sensibility detected for progesterone was $0.004 \mathrm{ng} / \mathrm{ml}$ and for estradiol was $0.00014 \mathrm{ng} / \mathrm{ml}$. Progesterone intra-assay coefficient was $2.58 \%$ and $6.36 \%$ and inter-assay was $0.67 \%$ and $5.55 \%$. Estradiol intra-assay coefficient was $0.69 \%$ and $4.15 \%$, and inter-assay was $1.40 \%$ and $3.00 \%$. Parallelism was used for kits validation. Progesterone and DPC commercial kit Parallelism was $\mathrm{r}=0.96$ for Leopardus pardalis and $\mathrm{r}=0.99$ for Leopardus tigrinus. Estradiol and DSL commercial kit Parallelism was $r=0.98$ for L eopardus pardalis and $\mathrm{r}=0.99$ for Leopardus tigrinus. In conclusion, these results showed that DPC commercial kit for serum progesterone dosages and DSL commercial kit for serum estradiol dosages can be used for Leopardus pardalis e Leopardus tigrinus. These findings are potentially valuable for the reproductive management and conservation of endangered felid populations.

\section{Referências}

1 SEAL, U. S.; PLOTKA, E. D.; SMITH, J. D.; WRIGHT, F. H.; REINDL, N. J.; TAYLOR, R. S.; SEAL, M. F. Immunoreactive luteinizing hormone, estradiol, progesterone, testosterone and androstenedione levels during the breeding season and anestrus in Siberian tigers. Biology of Reproduction, v. 32, p. 361-368, 1985.

2 EWER, R. F. The evolution of mating system in the felidae. In: EATON, R. L. The world's cats: biology, behavior and management of reproduction. London: Unimark Publishing, 1975. p. 11-20.

3 JOHNSTON, S. D.; ROOT, M. V.; OLSON, P. N. S. Ovarian and testicular function in the domestic cat: clinical management of spontaneous reproductive disease. Animal Reproduction Science, v. 42, p. 261274, 1996.

4 SHILLE, V. M.; LUNDSTROM, K. E.; STABENFELDT, G. H. Follicular function in the domestic cat as determined by estradiol-17b concentrations in plasma: relation to estrous behavior and cornification of exfoliated vaginal epithelium. Biology of Reproduction, v. 21 , p. $953-963,1979$.

5 SCHMITH, A. M.; HESS, D. L.; SCHMITH, M. J.; LEWIS, C. R. Serum concentration of oestradiol and progesterone and frequency os sexual behavior during the normal oestrous cycle in the snow leopard (Panthera uncia). Journal Reproduction and Fertility, v. 98, p. 91-95, 1993.

6 WILDT, D. E.; PLATZ, C. C.; CHAKRABORTY, P. K.; SEAGER, S. W. J. Oestrous and ovarian activity in a female jaguar (Panthera onca). Journal Reproduction and Fertility, v. 56, p. 555-558, 1979.
7 BONNEY, R. C.; MOORE, H. D. M.; JONES, D. M. Plasma concentrations of oestradiol-17b and progesterone, and laparoscopic observations of the ovary in the puma (Felis concolor) during oestrus, pseudopregnancy and pregnancy. Journal of Reproduction and Fertility, v. 63, p. 523-532, 1981.

8 SCHMITH, A. M.; HESS, D. L.; SCHMITH, M. J.; SMITH, R. C.; LEWIS, C. R. Serum concentration of oestradiol and progesterone, and sexual behavior during the normal oestrus cycle in the leopard (Panthera pardus). Journal Reproduction and Fertility, v. 82, p. 43-49, 1988.

9 MORAIS, R. N.; MOREIRA, N.; MUCCIOLO, R. G.; LACERDA, O.; GOMES, M. L. F.; SWANSON, W. F.; GRAHAM, L. H.; BROWN, J. L. Testicular and ovarian function in south American small felids assessed by fecal steroids. In: ANNUAL MEETING OF THE AMERICAN ASSOCIATION OF ZOO VETERINARIANS, 1996, Puerto Vallarta. Proceedings... Puerto Vallarta, México: American Association of Zoo Veterinarians, 1996. p. 561-565.

10 MOREIRA, N.; MONTEIRO-FILHO, E. L. A.; MORAES, W.; SWANSON, W. F.; GRAHAM, L. H.; PASQUALI, O. L.; GOMES, M. L. F.; MORAIS, R. N.; WILDT, D. E.; BROWN, J. L. Reproductive steroid hormones and ovarian activity in felids of the Leopardus Genus. Zoo Biology, v. 20, p. 103-116, 2001.

11 PAZ, R. C. R.; DIAS, E. A.; ADANIA, C. H.; BARNABE, V. H.; BARNABE, R. C. Ovarian response to repeated administration of alternating exogenous gonadotropin regimens in the ocelot (Leopardus pardalis) and tigrinus (Leopardus tigrinus). Theriogenology, v. 66, p. 1787-1789, 2006.

12 PAZ, R. C. R.; SWANSON, W. F.; DIAS, E. A.; ADANIA, C. H.; BARNABE, V. H.; BARNABE, R. C. 
Ovarian and immunological responses to alternating exogenous gonadotropin regimens in the ocelots (Leopardus pardalis) and tigrina (Leopardus tigrinus). Zoo Biology, v. 24, p. 247-260, 2005.

13 DARBRE, P.; YATES, J.; CURTIS, S.; KING, R. J. B. Effect of estradiol on human breast cancer cells in culture. Cancer Research, v. 43, p. 349-354, 1983.

14 REDDEL, R. R. MURPHY, L. C.; SUTHERLAND, E. L. Factors affecting the sensitivity of T-47 human breast cancer cell to tamoxifen. Cancer Research, v. 44, p. 2398-2405, 1984.

15 BROWN, J. L. Endocrine manual for hormonal assessment of wildlife species. Front Royal, VA: Endocrine Research Laboratory, Conservation \& Research Center, National Zoological Park, 2008. 65 p. Apostila.

16 GRAHAM, L. H. Non invasive monitoring of reproductive hormones in zoo and wildlife species. Jaboticabal: Faculdade de Ciências Agrárias e Veterinárias do Campus de Jaboticabal - UNESP, 2001. 18 p. Apostila.

17 ASHER, G. W.; PETERSON, A. J.; DUGANZICH, D. Adrenal and ovarian sources of progesterone secretion in young female fallow deer, Dama dama. Journal of Reproduction and Fertility, v. 85, p. 667675, 1989.

18 BERTSCHINGER, H. J.; TRIGG, T. E.; JÖCHLE, W.; HUMAN, A. Induction of contraception in some African wild carnivores by dowregulation of $\mathrm{LH}$ and $\mathrm{FSH}$ secretion using the $\mathrm{GnRH}$ analogue desnorelin.
Journal of Reproduction and Fertility, v. 60, p. 41-52, 2002. Supplement.

19 JOHNSTON, S. D.; KUSTRITZ, M. V. R.; OLSON, P. N. S. Canine and feline theriogenology. Philadelphia: W. B. Saunders, 2001. p. 396-405.

20 TEBET, J. M. Aspectos clínicos e fisiológicos do ciclo estral da jaguatirica (Leopardus pardalis, L.1758). 1999. 102 f. Dissertação (Mestrado em Reprodução Animal) - Faculdade de Medicina Veterinária e Zootecnia, Universidade Estadual Paulista "Júlio de Mesquita Filho", Botucatu, 1999.

21 MORAES, W.; MORAIS, R.; MOREIRA, N.; LACERDA, O.; GOMES, M.L.F.; MUCCIOLO, R. G.; SWANSON, W. F. Successful artificial insemination after exogenous gonadotropin treatment in the ocelot (Leopardus pardalis) and tigrina (Leopardus tigrina). In: AMERICAN ASSOCIATION OF ZOO VETERINARIANS ANNUAL MEETING, 1997, Houston, Texas. Proceedings... 1997. p. 334-336.

22 GRAHAM, L. H.; SWANSON, W. F.; BROWN, J. L. Chorionic gonadotropin administration in domestic cats causes an abnormal endocrine environment that disrupts oviductal embryo transport. Theriogenology, v. 54, p. 1117-1131, 2000.

23 PAZ, R. C. R. Biotecnologias da reprodução utilizadas como ferramentas auxiliares no manejo e conservação de duas espécies de felinos: Leopardus pardalis e Leopardus tigrinus. 2004. $148 \mathrm{f}$. Tese (Doutorado) - Faculdade de Medicina Veterinária e Zootecnia, Universidade de São Paulo, São Paulo, 2004. 